Journal of Patient-Centered

\title{
Improving Health and Well-Being: Connecting Research and Practice. The 24th Annual Conference of the Health Care Systems Research Network
}

Karen L. Margolis

Nico Pronk

Jane E. Duncan

Sarah M. Greene

Follow this and additional works at: https://aah.org/jpcrr

Part of the Clinical Epidemiology Commons, Community Health and Preventive Medicine Commons, Health Information Technology Commons, Health Services Research Commons, Medical Education

Commons, Medical Specialties Commons, Other Medicine and Health Sciences Commons, and the Public Health Education and Promotion Commons

\section{Recommended Citation}

Margolis KL, Pronk N, Duncan JE, Greene SM. Improving health and well-being: connecting research and practice. The 24th annual conference of the Health Care Systems Research Network. J Patient Cent Res Rev. 2018;5:244-7. doi: 10.17294/2330-0698.1641

Published quarterly by Midwest-based health system Advocate Aurora Health and indexed in PubMed Central, the Journal of Patient-Centered Research and Reviews (JPCRR) is an open access, peer-reviewed medical journal focused on disseminating scholarly works devoted to improving patient-centered care practices, health outcomes, and the patient experience. 


\title{
Improving Health and Well-Being: Connecting Research and Practice. The 24th Annual Conference of the Health Care Systems Research Network
}

\author{
Karen L. Margolis, MD, MPH, Nico Pronk, PhD, Jane E. Duncan, MPH, Sarah M. Greene, MPH \\ HealthPartners Institute, Minneapolis, MN
}

\begin{abstract}
The 24th annual conference of the Health Care Systems Research Network (HCSRN, formerly the HMO Research Network), held April 11-13, 2018, in Minneapolis, Minnesota, attracted 357 attendees. The HCSRN is a consortium of 18 community-based research organizations embedded in or affiliated with large health care delivery systems. Its annual research conference, held since 1994, is a unique venue that brings diverse stakeholders (eg, research teams, clinicians, patients, funders) together to explore a range of health research topics and scientific findings, with a unifying goal of connecting applied research to real-world care delivery for the betterment of individual and community health.

The 2018 conference was hosted by Minneapolis-based HealthPartners Institute and organized around 3 tracks: Research \& Results, Practical Application, and Data Science \& Informatics. Themes of the 4 plenary, 7 panel, 36 oral abstract, and 111 poster presentations included the learning health system, the opioid epidemic, health disparities, high costs of care, informing population health policy with evidence, and how to use storytelling to present data to inspire change, among others. ( $\mathrm{J}$ Patient Cent Res Rev. 2018;5:244-247.)
\end{abstract}

Keywords learning health system, health disparities, costs of care, population health, health services research, health care, patient engagement

$\mathrm{L}$ earning health systems continuously and systematically integrate internal data and research results into practice to improve care quality and safety, efficiency, and work culture. ${ }^{1}$ When these real-world systems join together to conduct population-based research, they are able to amplify and broadly disseminate findings that improve health and well-being. The Health Care Systems Research Network (HCSRN, formerly the HMO Research Network) is a consortium of 18 community-based research organizations (17 in the United States and 1 in Israel) embedded in or affiliated with large health

Correspondence: Sarah M. Greene, MPH, HealthPartners Institute, Mailstop 23301A, P.O. Box 1524, Bloomington, MN 55440 (sarah.m.greene@HealthPartners.com) care delivery systems. HCSRN membership consists of more than 1900 delivery system-based scientists and research staff, offering a unique forum to bring the learning health system concept to fruition.

The HCSRN's mature research infrastructure supports efficient and effective approaches to collaborating on an array of research topics. By pooling data from electronic health records, claims, and other sources through the use of standardized virtual data warehouses, a stable population base can be observed over time and across care settings. ${ }^{2}$ This approach blends agility and data security, and fosters real-time learning as data are used for research projects.

Each year since its inception in 1994, the HCSRN has held an annual conference to bring together researchers, project staff, funders, and other stakeholders to share 
the latest scientific findings and spark new research ideas, collaborations, and partnerships between research teams, patients, and clinicians. ${ }^{2}$ The 2018 HCSRN Conference took place in Minneapolis, Minnesota, from April 11 to 13.

\section{Conference Structure}

HealthPartners Institute (Minneapolis, MN) helped shape the conference's content and structure as host of the event, which attracted more than 350 attendees and was organized under the theme "Improving Health and Well-Being: Connecting Research and Practice." The conference was organized around three tracks: Research \& Results, Practical Application, and Data Science \& Informatics. Themes of the 4 plenary, 7 panel, 36 oral abstract and 111 poster presentations included, among others, the continuously learning health system, best practices for data sharing and collaboration, the opioid epidemic, health disparities, the high costs of care, informing population health policy with evidence, and how to use storytelling to present data to inspire change.

Poster sessions were organized under the topics aging and multimorbidity; cancer; cardiovascular disease; care improvement; child and adolescent health; data science, informatics, and data models; diabetes, obesity, and other chronic conditions; genetics, genomics, and precision medicine; health disparities; health policy; health services delivery, utilization, and coverage; implementation science; maternal and perinatal care; mental health, alcohol, and substance use/abuse; methods, designs, and analytic tools; patient, clinician, and health system engagement; and population, community, and worksite health. This range illustrates the breadth of scientific expertise across the 18 HCSRN member organizations, and offers a rich and diverse slate of ideas for all attendees to consider and discuss with their peers during and after the conference.

Conference organizers carefully crafted the conference program to attract both HCSRN and non-HCSRN researchers. ${ }^{2}$ The commonality of the HCSRN is that it is an organization of "embedded" researchers, scientists who conduct health science research through their positions inside health care systems. However, it is important to also attract researchers from organizations outside the HCSRN, such as academic institutions, public health departments, funding organizations, and the Department of Veterans Affairs, who can provide additional perspectives and might also benefit from attending the conference.

The research-to-practice connection was a central focus of the conference and drove the selection of its theme and format. While the theme varies from year to year, a cornerstone of the conference is to identify and share generalizable findings and insights about how findings can be applied in real-world care delivery settings. Given that one-third of the attendees were from non-HCSRN organizations, it is clear that this aspect of the conference has wide appeal beyond the network members themselves.

In 2018, a total of 167 abstracts were submitted in response to the call for abstracts on scientific findings. To share HCSRN activities with a broader audience, accepted abstracts were published concurrently with the conference in a supplement to volume 5, issue 1 of the Journal of Patient-Centered Research and Reviews. ${ }^{3}$

\section{Plenary Sessions}

The first plenary session was led by J. Michael McGinnis, MD, MA, MPP, of the National Academy of Medicine. Dr. McGinnis is an international health policy and programs expert who has held positions under four presidential administrations and was the developer of the continuously learning health system concept and the Healthy People program. In his presentation, "Advancing the Continuously Learning Health System: A National Academy of Medicine Perspective," he discussed the elements of a learning health system, related activities to advance progress, and highlighted priorities for the future. Data and applied analytics are a critically important facet of health system learning, and Dr. McGinnis observed that HCSRN efforts in pharmacoepidemiology were a particularly important contribution.

Another plenary session featured Ed Ehlinger, MD, former commissioner for the Minnesota Department of Health; Jan Malcolm, current and former Minnesota health commissioner; and Sanne Magnan, MD, $\mathrm{PhD}$, senior research fellow at HealthPartners Institute and former Minnesota health commissioner. The panel discussion, "Fireside Chat With Minnesota Health 
Commissioners: Perspectives on Informing Population Health Policy With Evidence," focused on how to reverse trends such as eroding life expectancy and significant health inequities, which threaten the goals of physical, mental, social, and spiritual well-being for all. The commissioners, who served under three different administrations (Democrat, Republican, and Independent), also highlighted gaps in the science and research needed for the evidence base to create better population health and a sustainable, affordable health care system. The session was moderated by Stephen Fortmann, MD, senior director of science programs at the Kaiser Permanente Center for Health Research (Portland, OR).

The third plenary session, led by Sarah Greene, MPH, executive director of the HCSRN, consisted of the annual State of the Network Address and Awards Presentation. In this presentation, Ms. Greene described how the HCSRN has adapted to the changing landscape of health care by leveraging its size, diversity, and versatility. She noted that connections between attendees, including patients, clinicians, and researchers, are the fuel for shared learning and collaboration.

The final session, "Arts Integrated Resources: Blending Story With Data to Inspire Change," featured a team from Kaiser Permanente Colorado (Denver, CO) consisting of Betty Hart and Curtis Robbins from Arts Integrated Resources and Leslie Wright from the Institute for Health Research. The workshop leaders offered experiential activities showing how a well-told story can persuade people to think about situations differently and even change their minds. They discussed how to blend in storytelling elements to turn research findings into retainable, heartfelt stories that can be used for teaching and motivation. They also shared a useful "recipe card" to think about the intended audience, objective, data elements, story elements, and desired take-home messages.

\section{Other Highlights}

In response to feedback on the 2017 conference, the 2018 conference planners offered both panels and oral presentations of the conference's highest-rated scientific abstracts. Panel presentations represented a diverse mix of topics. On day 1 , conference attendees could choose between panels discussing training new researchers in delivery system science, development of a new summary measure of health and well-being, and conducting randomized trials in partnership with health systems to improve care for high-need patients. On day 2, panel offerings included promoting collaboration through data-sharing innovations, deimplementation of low-value care, a multicenter trial of collaborative care for opioid use disorders, and an overview on qualitative research methods. Similarly, the scientific abstracts, while grouped by theme, showcased a diverse range of high-priority topics in health care, including health equity, pain management, maternal and child health, and stakeholder engagement efforts for care improvement.

A vital part of the conference is the convening of scientific interest group meetings and similar ancillary meetings at which researchers come together to discuss a specific new project, review progress on an existing project, or share insights and best practices in a specific domain (eg, patient engagement, data science). ${ }^{2}$ This year, 18 groups convened formally, with other impromptu meetings deriving from new connections and shared interests. Notably, 25 new organizations attended this year, and more than 126 attendees joined for the first time.

As it has matured, the HCSRN has expanded awards and honors bestowed at the conference. This year's event presented awards for mentor of the year, best poster from each of the two sessions, early career investigator, best research paper, and honorary service. Recipients were:

- HCSRN Mentor of the Year: Kathleen Mazor, EdD, Meyers Primary Care Institute (Worchester, MA)

- Best Posters: Hsueh-Han Yeh, MS, and Farah Elsiss, MS, both of Henry Ford Health System (Detroit, MI)

- Early Career Investigator Award: Daniel Maeng, PhD, Geisinger (Danville, PA)

- Best HCSRN Paper of 2017: Elyse Kharbanda, MD, MPH, HealthPartners Institute

- Honorary Service Award: Harold Luft, PhD, Palo Alto Medical Foundation Research Institute (Palo Alto, CA)

Finally, new for 2018, the conference offered continuing medical education credits for physicians and Minnesota pharmacists. 


\section{HCSRN 2019}

Planning is underway for the next HCSRN annual conference, scheduled for April 8-10, 2019, in Portland, Oregon. Under the theme "Celebrating Health Research," the conference will recognize 25 years of research that supports better health and health care. The conference is open to everyone in the research community, including those from nonmember sites, clinicians, patient partners, federal and industry partners, and others interested in improving health care for all. For more information or to join the conference updates email list, please visit hcsrnmeeting.org.

A key enduring value of the HCSRN conference is to provide a venue to share scientific, methodological, and operational insights in support of the mission to improve care. This conference is a rare venue for applied delivery system science and will continue in its mission of outstanding research that can influence and improve health care.

\section{Acknowledgments}

The authors thank the 2018 HCSRN Conference planning committee, management team at Conference Solutions (Portland, OR), and HCSRN governing board for their contributions and support. We gratefully acknowledge financial sponsorship from the Patient-Centered Outcomes Research Institute (Washington, DC). Finally, we thank the HealthPartners Institute employees who served as volunteers. The smooth execution of the conference would not have been possible without their dedicated efforts.

\section{Conflicts of Interest}

None.

\section{References}

1. Agency for Healthcare Research and Quality. Learning health systems. (Content last reviewed November 2017.) http://www. ahrq.gov/professionals/systems/learning-health-systems/ index.html. Accessed May 1, 2018.

2. Luft HS, Tai-Seale M, Greene SM. Advancing learning health systems through embedded research: the 23rd annual conference of the Health Care Systems Research Network. $J$ Patient Cent Res Rev. 2017;4:139-43. CrossRef

3. Abstracts from the 24th annual Health Care Systems Research Network Conference, April 11-13, 2018, Minneapolis, Minnesota. J Patient Cent Res Rev. 2018;5:56-131. CrossRef

(C) 2018 Aurora Health Care, Inc. 